\title{
Income Distribution and Growth in Leontief's Closed Model
}

\author{
Alberto Benítez Sánchez \\ Economics Department, Universidad Autónoma Metropolitana, Mexico City, Mexico \\ Email: abaxayacatl3@gmail.com
}

Received 5 December 2015; accepted 14 January 2016; published 19 January 2016

Copyright (C) 2016 by author and Scientific Research Publishing Inc.

This work is licensed under the Creative Commons Attribution International License (CC BY). http://creativecommons.org/licenses/by/4.0/

(c) (i) Open Access

\begin{abstract}
While the routine use of Leontief's closed model is limited to the case in which the whole income of an economy goes to wages, this paper shows that the model also permits the representation of production programs corresponding to every level of income distribution between wages and profits. In addition, for each of these programs, the model allows calculating the price system and the profit rate when this rate is the same in all industries. Thus, the results obtained in Sraffa's surplus economy are established following an alternative way, this makes it possible to build a particular standard system for each level of income distribution between wages and profits. Besides, the fact that the model includes the set of households as a particular industrial branch permits to build a balanced-growth path of the economy in which the quantities of work used in each industry as well as the goods consumed by the workers are studied explicitly, unlike what happens in von Neumann's model. The paper also shows that, under a weak assumption, the balanced-growth rate is independent of the worker's choice.
\end{abstract}

\section{Keywords}

Income Distribution, Leontief's Closed Model, Sraffa's Standard Commodity, von Neumann's Balanced-Growth Path

\section{Introduction}

In the specialized literature, Leontief's closed model is an instrument of analysis applied mainly to calculate certain relations between inputs and outputs in an industrial system and also to calculate prices in the particular case when all the income goes to wages (e.g., Berman \& Plemmons [1], pp. 258-265; Dorfman, et al. [2], pp. 245-264; Leontief [3], pp. 33-65; ten Raa [4], pp. 11-12). In this paper, I show that it is also possible to use it to calculate the price system and the profit rate corresponding to every level of income distribution between wages and profits when the rate of profit is the same in all industries. In this manner, the results obtained in Sraffa [5] 
regarding surplus economies are established following an alternative way that, contrarily to Sraffa's model, makes it possible to build a particular standard system for every level of the profit rate. A distinctive feature of Leontief's closed model is that the set of households are included as a particular branch of industry whose inputs are the goods consumed by workers and whose output is work. Following this approach, I assign to the set of households the rate of profit common to the industrial system. In the steady state, this procedure is an accounting devise facilitating the analysis whereas, in the balanced-growth path, the profit rate measures the growth of the quantity of labor provided by the set of households.

Including this introduction, the paper is divided in 9 sections and an Appendix. Sections 2 and 3 present respectively the open and the closed Leontief's model. Section 4 studies prices and income distribution in Leontief's closed model when the profit rate is the same in all industries. Section 5 presents within the model the equality established by von Neumann [6] between the profit and growth rates. Section 6, shows that, by adopting a week assumption, the balanced-growth rate is independent of consumers' choice. Section 7 studies the balanced-growth path which corresponds to Leontief's closed model. Section 8 points out the existence of a particular standard system for each level of the profit rate. The main conclusions are summarized in Section 9 and the Appendix illustrates certain results through a numerical example.

\section{Leontief's Open Model}

The reference economy is integrated by $n(n \geq 1)$ industries, each one producing a particular type of good labeled $i$ or $j$ so that $i, j=1,2, \cdots, n$. I will also refer to indexes as goods. A set of indexes $\{j 1, j 2, \cdots, j D\}$ is a D-set if it contains $D$ different goods, for any particular D-set, $d=1,2, \cdots, D$. For each pair $(i, j)$ and for each $j, a_{i j}$ and $l_{j}$ are respectively the quantity of $i$ and the quantity of labor consumed directly in the production of one unit of $j$. Regarding these technical coefficients, I assume that $a_{i j} \geq 0$ for every $(i, j)$ and that, for each $j$ :

$$
\begin{gathered}
a_{i j}>0 \quad \text { at least for one } i, \\
l_{j}>0 .
\end{gathered}
$$

For each $j, p_{j}$ is the price of good $j, z_{j}$ is the sum of wages and profits corresponding to branch $j$ per unit of good, $x_{j}$ is the quantity of $j$ produced in the corresponding industry, and $c_{j}$ is the difference between this quantity and the amount of the same good that is consumed in the industrial system during the period being considered. It is useful to write these quantities in matrix notation defining the column vectors $p=\left(p_{1}, p_{2}, \cdots, p_{n}\right)^{\mathrm{T}}$, $z=\left(z_{1}, z_{2}, \cdots, z_{n}\right)^{\mathrm{T}}, \quad x=\left(x_{1}, x_{2}, \cdots, x_{n}\right)^{\mathrm{T}}$, and $c=\left(c_{1}, c_{2}, \cdots, c_{n}\right)^{\mathrm{T}}$, together with the input matrix $A=\left[a_{i j}\right]$. This permits the representation of the relations between inputs and outputs of the different goods and the relation between each price and its production cost, respectively, by means of the following equation systems.

$$
\begin{gathered}
A x+c=x, \\
A^{\mathrm{T}} p+z=p .
\end{gathered}
$$

The Frobenius roots of matrices $A$ and $A^{\mathrm{T}}$, which are equal, are represented with $\lambda_{A}$. Furthermore, given two matrices $(A, B)$ or two vectors $(x, y)$, the relations $A>B$, and $x>y$ means respectively that $a_{i j}>b_{i j}$ for every couple $(i, j)$ and $x_{i}>y_{i}$ for every $i$. I define each one of the relations " $<$ ", " $\geq$ ”, and " $\leq$ ", in a similar manner. A vector $x$ is positive if $x>0$ and semi-positive if $x \geq 0$ and $x \neq 0$, similar definitions are valid for matrices and positive scalars. If all the entries of a matrix or a vector are equal to zero it may be represented by 0 .

Moving along to the topic of viability, a square matrix $A \geq 0$ may be interpreted as an input matrix corresponding to an economy that produces one unit of each good. Assuming this interpretation, and in order to simplify, I will refer to any such matrix as a technique even if the labor amounts are not indicated. Also, I will say that the technique is viable if:

$$
\lambda_{\mathrm{A}}<1 .
$$

Condition (1) implies that in the economy there is at least one good that produces itself either directly or indirectly (see Lemma 1.1 by Seneta [7], p. 16). For this reason, either $A$ is indecomposable or, in the canonical form of $A$, there is at least one indecomposable matrix. In both cases, we have: 


$$
0<\lambda_{A} .
$$

Equation (3) is an economy or a production program reproducing itself if it produces all the inputs consumed, in which case $x \geq 0, x \neq 0$, and $c \geq 0$. Such an economy is open if $c \neq 0$ and is viable if matrix $A$ is a viable technique. I assume that (3) and (4) represent a viable open economy.

If some goods are not produced, it is possible to eliminate from the program the equations corresponding to those goods together with the coefficients corresponding to them in the remaining equations. Then, reassigning the indexes among the goods produced, a new program results where $x>0$. For this reason, without loss of generality, I assume that $x>0$.

Given that vector $c$ represents the net product, I will say that a good $i$ is in the net product if $c_{i}>0$. The following proposition relates production and consumption.

Proposition 1. In a viable open economy every good either is in the net product or produces at least one good that is in the net product, or both.

Proof. Given any $i$, consider the D-set consisting of $i$ and all the goods produced by $i$ either directly or indirectly. If $D=n$, the proposition is true for $i$ because $c \neq 0$. On the other hand, if $D<n$, assuming that the proposition is not true contradicts (5). Indeed, in this case, by means of simultaneous permutations of columns and rows, the columns and rows $j 1, j 2, \cdots, j D$, in this order, are placed in the first $D$ positions. Then, it is possible to write matrix $A$ as follows:

$$
\left[\begin{array}{ll}
E & F \\
G & H
\end{array}\right] .
$$

In which $E$ is the square matrix formed by the intersection of the first $D$ columns and the first $D$ rows, $H$ is a $(n-D) \times(n-D)$ square matrix and $F=0$ because, by definition, goods belonging to $\mathrm{D}$ do not produce the goods not belonging to $\mathrm{D}$. These results, together with the fact that $c_{j d}=0$ for every $d$ such that $1 \leq d \leq D$, imply the equation $E x^{\mathrm{D}}=x^{\mathrm{D}}$ where $x^{\mathrm{D}}=\left(x_{j 1}, x_{j 2}, \cdots, x_{j D}\right)^{\mathrm{T}}$. Given that $x>0$, we have $x^{\mathrm{D}}>0$. Thus, the Frobenius root of $E$ is greater than or equal to one, a result allowing to conclude that $\lambda_{A} \geq 1$, contradicting (5).

The model presented in this section constitutes the basis on which Leontief's closed model is to be built in the next section. We shall see Proposition 1 allows the establishing of some important properties of the closed model.

\section{Leontief's Closed Model}

In this section, Leontief's closed model is built by adding to the model presented in the previous section the data from the set of households considered as an industrial branch. For this purpose, we will define first some additional notation.

For each $j \leq n$, let:

$$
a_{n+1, j}=l_{j}
$$

and, for each $i \leq n$, let:

$$
a_{i, n+1}=c_{i} / \sum_{j} x_{j} l_{j} .
$$

Therefore, for each $j, a_{n+1, j}$ is the quantity of labor consumed per unit of $j$ produced and for each $i, a_{i, n+1}$ is the quantity of $i$ in the net product per unit of labor employed. Assumption (2) must be kept in mind regarding these coefficients and also the fact that $c_{i}>0$ for at least one $i$. Hence, the following conditions are satisfied:

$$
\begin{gathered}
a_{n+1, j}>0 \text { for each } j \leq n, \\
a_{i, n+1}>0 \text { at least for one } i \leq n .
\end{gathered}
$$

As explained below, Leontief assumes that:

$$
a_{n+1, n+1}=0 \text {. }
$$

We can use the information from the program to form the following matrix:

$$
Æ=\left[\begin{array}{cc}
A & \omega C \\
L & 0
\end{array}\right] .
$$


in which $A$ is the matrix of means of production coefficients, $\omega \geq 0$ is usually equal to one, as we assume in this section, but may adopt other values as indicated in the next one, $C$ is the $n \times 1$ matrix $\left[a_{1, n+1}, a_{2, n+1}, \cdots, a_{n, n+1}\right]^{\mathrm{T}}$ and $L$ is the $1 \times n$ matrix $\left[a_{n+1,1}, a_{n+1,2}, \cdots, a_{n+1, n}\right]$. Each row $i$ of matrix $Æ$ indicates quantities of good $i$ consumed by the different industries and each column $j$ indicates inputs consumed by industry $j$. Regarding this, special attention must be paid to column $n+1$ and row $n+1$ of $Æ$ because they correspond respectively to the set of households considered by Leontief as a particular industry whose product is work and whose inputs are the goods in the net product. He assumes that households do not use labor, which implies (12).

Let $q=\left(q_{1}, q_{2}, \cdots, q_{n+1}\right)^{\mathrm{T}}$. The equation:

$$
Æ q=q
$$

has a solution $q>0$ in which, for each $j \leq n, q_{j}=x_{j}$ is the quantity of $j$ produced and $q_{n+1}=\sum_{j} x_{j} l_{j}$ is the quantity of labor produced. It is important to observe that the following conditions are satisfied:

$$
\begin{gathered}
Æ \text { is indecomposable, } \\
\lambda_{Æ}=1 .
\end{gathered}
$$

Indeed, it follows from Proposition 1 that each good $i$ such that $i \leq n$ produces Good $n+1$ and, according to (1), Good $n+1$ produces every good. For this reason, each good produces every good which implies (15). On the other hand, according to (iv) of Theorem 4.B.1 by Takayama ([8], p. 372), the fact that Equation (14) has a solution $q>0$ together with (15) implies (16).

Regarding the price system, let $p_{n+1}$ be the price of one unit of labor and $p^{+}=\left(p_{1}, p_{2}, \cdots, p_{n+1}\right)^{\mathrm{T}}$. Due to (15) and (16), according to (ii) and (iii) from the theorem just quoted, the equation:

$$
Æ^{\mathrm{T}} p^{+}=p^{+},
$$

has a solution $p^{+}>0$ determined up to a scalar factor. In this system, the price of each good is equal to the cost of the inputs consumed to produce the good.

\section{Income Distribution in Leontief's Closed Model}

If the profit rate $(r)$ is the same in all industries, and if wages are paid at the beginning of production, for each $j$, the following equation is true:

$$
z_{j}=\sum_{i} a_{i j} p_{i} r+a_{n+1, j} p_{n+1}(1+r)
$$

Hence, it is possible to write (4) as follows:

$$
\sum_{i} a_{i j} p_{i}(1+r)+a_{n+1, j} p_{n+1}(1+r)=p_{j} \quad j=1,2, \cdots, n
$$

By measuring prices using the value of the net product, the following equation is satisfied:

$$
\sum_{i} c_{i} p_{i}=1 \text {. }
$$

In connection to this, let $\mathrm{w}$ be the fraction of the value of the net product equivalent to the total wages paid. Multiplying both sides of (20) by w yields:

$$
\sum_{i} \mathrm{w} c_{i} p_{i}=\mathrm{w}
$$

Dividing both sides of this equation by $\sum_{i} x_{i} l_{i}$ results in:

$$
\sum_{i} \mathrm{w}\left[c_{i} / \sum_{i} x_{i} l_{i}\right] p_{i}=\mathrm{w} / \sum_{i} x_{i} l_{i}
$$

Substituting in this equation, for each $i$, the term in brackets by the left-hand side of (9), and in addition, the right-hand side of the equation by $p_{n+1}$, yields:

$$
\sum_{i} \mathrm{w} a_{i, n+1} p_{i}=p_{n+1} \text {. }
$$


Furthermore, let $\omega$ be the fraction of the value of the net product that, paid at the beginning of production, is equivalent to $\mathrm{w}$ at the end of it. Then:

$$
\mathrm{w}=\omega(1+r) .
$$

The auxiliary variable $\omega$ permits to write (23) in a way that is appropriate for Leontief's closed model. Indeed, substituting $w$ in (23) by the right-hand side of (24) results in:

$$
\sum_{i} \omega a_{i, n+1} p_{i}(1+r)=p_{n+1} \text {. }
$$

Now, let:

$$
\lambda_{\text {Æ }}=1 /(1+r) .
$$

Then, it is possible to write the system formed by Equations (19) and (25) as follows:

$$
Æ^{\mathrm{T}} p^{+}=\lambda_{Æ} p^{+} .
$$

The coefficients that are greater than zero in $Æ$ when $\omega=1$ also are greater than zero for every $\omega>0$. Therefore, for each of these values of $\omega$, proposition (15) is true. Due to condition (11), for every $\omega \geq 0$, whenever $\omega$ increases, at least one coefficient of $Æ$ increases and no coefficient decreases. For this reason, according to (vi) from Theorem 4.B.1 by Takayama ([8], p. 372), also $\lambda_{\digamma}$ increases. Furthermore, as can be observed in Equation (13), the value of $\lambda_{\text {F }}$ is equal to $\lambda_{\mathrm{A}}$ when $\omega=0$. These results, along with Equation (16), and the fact that $\lambda_{\leftleftarrows}$ is a continuous function of the coefficients of $Æ$ (e.g., Serre [9], Theorem 3.1.2, p. 44; Zhang [10], Theorem 2.11, p. 68), permit us to establish the following conclusions.

Proposition 2. There is a continuous monotonic increasing function $\lambda_{E}=\lambda_{E}(\omega)$ associating to each $\omega \geq 0$ the Frobenius root of matrix $Æ$ for that particular $\omega$. This root is equal to $\lambda_{\mathrm{A}}$ when $\omega=0$ and is equal to one when $\omega=1$.

This proposition together with condition (6) imply that, for each $\omega \in[0,1]$, we have $0<\lambda_{\star}(\omega) \leq 1$ and $\lambda_{E}(\omega)=1$ only if $\omega=1$.Therefore, for each $\omega \in[0,1]$ Equation (26) determines a unique profit rate for $\lambda_{Æ}=\lambda_{Æ}(\omega)$. This rate is equal to zero when $\omega=1$ and is positive for every $\omega \in[0,1[$. Furthermore, as already indicated, for each $\omega \in] 0,1]$, proposition (15) is true. Thus, there is a vector $p^{+}>0$ determined up to a scalar factor that satisfies Equation (27). If $\omega \in] 0,1]$ and the corresponding values of $p^{+}$and $r$ are known, Equation (20) and Equation (24) allow calculating, respectively, the price system and the sum of wages, measured in terms of the net product. The values of these variables are also positive and determined univocally. We can summarize these results in the following manner.

Proposition 3. For each $\omega \in] 0,1]$, there is a unique vector $F_{1}(\omega)=\left(\lambda_{\star}, r, \mathrm{w}, p_{1}, p_{2}, \cdots, p_{n+1}\right)$ whose coordinates satisfy Equations (20), (24), (26) and (27). For each $\omega \in] 0,1]$, all the coordinates of $F_{1}(\omega)$ are positive except for $F_{1}(1)$ in which case $r=0$.

For the reasons given in Proposition 2 and in the paragraph below it, there is a monotonic decreasing function $r=r(\omega)$ associating to each $\omega \in[0,1]$ the value of $r$ being determined by Equation (26) for $\lambda_{\star}=\lambda_{\star}(\omega)$. Moreover, when $\omega=0$, the value of $r$ is a real number $R>0$. Therefore, $r$ adopts all the values in the interval $[0, R]$ when $\omega$ diminishes from one to zero. As $R$ is greater than $r(\omega)$ for every $\omega \in] 0,1]$, I will refer to $R$ as the maximum profit rate.

It follows from the preceding analysis that there is a monotonic decreasing function $\omega=\omega(r)$ associating to each $r \in[0, R$ [ the value of $\omega$ for which $r=r(\omega)$. Therefore, for each $r \in[0, R[$ there is only one vector $F_{1}[\omega(r)]$ and, due to the fact that $\omega(r)$ and $r(\omega)$ are each the inverse function of the other, the second coordinate in this vector is equal to the given value of $r$. For each $r \in\left[0, R\left[\right.\right.$, let $F_{2}(r)$ be the vector obtained substituting the second coordinate of $F_{1}[\omega(r)]$ by the corresponding value of $\omega(r)$. In these conditions, Proposition 3 permits us to formulate the following conclusion.

Proposition 4. For each $r \in\left[0, R\left[\right.\right.$, there is a unique positive vector $F_{2}(r)=\left(\lambda_{\mathbb{E}}, \omega, \mathrm{w}, p_{1}, p_{2}, \cdots, p_{n+1}\right)$ whose coordinates satisfy Equations (20), (24), (26) and (27). 
Now, let us consider the matrix $G=\left[Æ^{\mathrm{T}}(1+r)\right]$, i.e., the matrix that results from multiplying each coefficient of $Æ^{\mathrm{T}}$ by $(1+r)$. It follows from Equation (27) and from the previous analysis that, for each $r \in[0, R[$, the equation $G p^{+}=p^{+}$is satisfied by the price system and the value of $\omega$ in vector $F_{2}(r)$. Thus, for each $r \in\left[0, R\left[\right.\right.$, the Frobenius root of $G\left(\lambda_{\mathrm{G}}\right)$ is equal to one. Furthermore, due to (1) and (10), whenever $r$ increases, at least one coefficient belonging to one of the first $n$ rows of $G$ increases without any decrease among the coefficients of these rows. For this motive, since $G$ is indecomposable, $\lambda_{\mathrm{G}}$ can remain equal to one despite the increase in $r$ if and only if at least one coefficient of row $n+1$ decreases which, in turn, can occur if and only if the product $(1+r)$ decreases, as can be corroborated by analyzing Equations (11) and (25). This result, together with the fact that the interval $] 0,1]$ is the range of the product $\omega(1+r)$ as a function of $r$ over the interval $[0, R[$, and Equation (24), imply the following conclusion.

Proposition 5. There is a monotonic decreasing function $\mathrm{w}=\mathrm{w}(r)$ associating to each $r \in[0, R[$ the value of $\mathrm{w}$ in vector $F_{2}(r)$. The range of this function is the interval ]0,1].

Hence, there is a monotonic decreasing function $r=r(\mathrm{w})$ associating to each $\mathrm{w} \in] 0,1]$ the value of $r \in[0, R[$ for which $\mathrm{w}=\mathrm{w}(r)$. For this reason, for each $\mathrm{w} \in] 0,1]$, there is only one vector $F_{2}[r(\mathrm{w})]$ and, due to the fact that $\mathrm{w}(r)$ and $r(\mathrm{w})$ are each the inverse function of the other, the third coordinate in this vector is equal to the given value of $\mathrm{w}$. For each $\mathrm{w} \in] 0,1]$, let $F_{3}(\mathrm{w})$ be the vector obtained substituting the third coordinate of $F_{2}[r(\mathrm{w})]$ by the corresponding value of $r(\mathrm{w})$. In these conditions, Proposition 4 permits us to formulate the following conclusion.

Proposition 6. For each $\mathrm{w} \in] 0,1]$, there is a unique vector $F_{3}(\mathrm{w})=\left(\lambda_{\star}, \omega, r, p_{1}, p_{2}, \cdots, p_{n+1}\right)$ whose coordinates satisfy Equations (20), (24), (26) and (27). For each $\mathrm{w} \in] 0,1]$, all the coordinates of $F_{3}(\mathrm{w})$ are positive except for $F_{3}(1)$ in which case $r=0$.

Dornbush et al. ([2], pp. 245-247) place into question the possible uses of Leontief's closed model and respond by indicating the already mentioned applications, which are adopted also in the works published later (e.g., Abex and Perobelli [11]; Flissner [12]; Kiedrowski [13]; Wurtelle [14]). This section complements their answer by using the model to calculate the price system and the profit rate corresponding to each level of income distribution between wages and profits when the profit rate is the same in all industries. Given that Sraffa [5] studies precisely this problem in a setting equivalent to Leontief's open model, it can be said that this study extends his approach from the open to the closed model. It must be added that this remark refers only to the formal aspects of the models just mentioned and not to the historical aspects of their construction, such as the influence one author had upon the work of the other.

\section{Von Neumann's Equality between Growth and Profit Rates}

It follows from the preceding analysis that, for each $\omega \in] 0,1]$, the equation:

$$
Æ q=\lambda_{Æ} q
$$

has a solution $q>0$ determined up to a scalar factor. Fixing the magnitude of $q$ by means of the equation:

$$
\sum_{j} a_{n+1, j} q_{j}=\sum_{i} x_{i} l_{i},
$$

we get the quantities produced under a program of production using the same amount of work as in system (3).

System (28) can be written as follows:

$$
\begin{gathered}
\sum_{j} a_{i j} q_{j}+\omega a_{i, n+1} q_{n+1}=\lambda_{Æ} q_{i} \quad i=1,2, \cdots, n \\
\sum_{j} a_{n+1, j} q_{j}=\lambda_{Æ} q_{n+1} .
\end{gathered}
$$

Equations (26) and (31) imply that $q_{n+1}=(1+r) \sum_{j} a_{n+1, j} q_{j}$. Thus, for each $i$, we can substitute $q_{n+1}$ by the right-hand side of this equation in the product $\omega a_{i, n+1} q_{n+1}$ obtaining $\omega(1+r) a_{i, n+1} \sum_{j} a_{n+1, j} q_{j}$. Then, substituting in the right-hand side of this equation $\omega(1+r)$ by the left-hand side of Equation (24) permits us to write:

$$
\omega a_{i, n+1} q_{n+1}=\mathrm{w} a_{i, n+1}\left[\sum_{j} a_{n+1, j} q_{j}\right]
$$


Hence, for each $i$, the product $\omega a_{i, n+1} q_{n+1}$ indicates the amount of Good $i$ consumed by workers.

According to Equations (30) and (31), the ratio between the quantity produced of each good and the amount of the same good consumed is equal to $1 / \lambda_{\mp}$ for all the goods from which the program is homothetic. For a production program that meets Equations (30) and (31), using a different quantity of labor, just multiply the vector $q$ by such amount of labor divided by the right-hand side of Equation (29). In order to establish the relationship between prices and the distribution of income within the program that produces $q$, for each $i$, multiply equation $i$ in system (19) by the corresponding coordinate $q_{i}$ and Equation (25) by $q_{n+1}$, as shown below in Section 8 and also in the Appendix.

Furthermore, letting:

$$
\lambda_{\text {Æ }}=1 /(1+g),
$$

we can write Equations (30) and (31) in the following way:

$$
\begin{gathered}
\sum_{j} a_{i j} q_{j}(1+g)+\omega a_{i, n+1} q_{n+1}(1+g)=q_{i} \quad i=1,2, \cdots, n \\
\sum_{j} a_{n+1, j} q_{j}(1+g)=q_{n+1} .
\end{gathered}
$$

In the system formed by Equations (34) and (35), we can observe that, as a result of the production process, the amount of each good increased at a growth rate equal to $g$. Therefore, at the end of the production cycle, it is possible to start another cycle investing in each industry $(1+g)$ times the amount of each good used in the first. If this were to happen, and if, in addition, investments are held similarly at the beginning of each of the following cycles, the economy grows in what is known as the balanced-growth path. In this regard, for each $\omega \in] 0,1]$, Equations (26) and (33) imply the result established by von Neumann [6]:

$$
r=g \text {, }
$$

It is worth adding that, in accordance with what precedes, a hallmark of an economy that is in the balanced-growth path in Leontief's closed model is the growth of the labor force, while von Neumann's model considers only the growth of the other industrial branches.

\section{Growth Rate and Worker's Choice}

Since matrix A can be decomposable, condition (15) depends on Equation (2) and on the matrix $\omega C$. Now, Equation (2) is a feature of the technique used while, in turn, $\omega C$ can be interpreted in two ways. The first is to consider $\omega C$ as a bundle of goods actually consumed by workers, which simplifies the analysis. The second is to consider $\omega C$ as a bundle of goods equivalent to $(\omega / \mathrm{w}) p_{n+1}$, permitting us to calculate the prices and the profit rate regardless of the bundle of goods actually purchased by employees. However, after replacing $\omega C$ in $Æ$ by the fraction $(\omega / \mathrm{w})$ of the bundle of goods actually purchased by employees per unit of labor, condition (15) may not be satisfied, which can involve a different solution for Equations (27) and (28). For example, if $Æ$ is decomposable and the Frobenius's roots of the square matrices in the main diagonal of the canonical form of $Æ$ are not equal, the balanced-growth rate may be different. Since, in this case, the vector $q$ would contain some zeros, the procedure followed in this paper permits the calculation of the maximum rate of balanced-growth, i.e., one that allows all branches of the economy to grow at the same rate.

Nevertheless, the balanced-growth rate does not change if $\omega C$ is replaced in $Æ$ by the fraction $(\omega / \mathrm{w})$ of the basket of goods actually consumed by workers per unit of labor, under the single condition that it has a non-null quantity for each of the goods present in C. To show this, if necessary, I will follow von Neumann ([6], p. 3, assumption (9)), adding to the basket effectively consumed by workers an infinitesimal amount of some goods.

For any given level of salary $\left.\mathrm{w}_{1} \in\right] 0,1\left[\right.$, let $r_{1}, \omega_{1}$ and $p^{+}$be respectively the profit rate, the value of $\omega$ and the system of prices in vector $F_{3}\left(\mathrm{w}_{1}\right)$ (see Proposition 6). In addition, let $r_{1}=g_{1}$ and

${ }^{*} C=\left[{ }^{*} a_{1, n+1},{ }^{*} a_{2, n+1}, \cdots,{ }^{*} a_{n, n+1}\right]^{\mathrm{T}}$ where, for each $i$ :

$$
{ }^{*} a_{i, n+1}={ }^{*} c_{i} / \mathrm{w}_{1} \sum_{j} x_{i} l_{j} .
$$


In this formula, for each $i$, if $i$ is consumed by workers ${ }^{*} c_{i}$ is the quantity consumed, if $c_{i}>0$ and $i$ is not consumed by workers ${ }^{*} c_{i}$ is an infinitesimal amount of said good and is zero at the cases remaining. It is important to note that, for each $i$, multiplying the right-hand side of system (37) by $\omega_{1}\left(1+r_{1}\right)$ results the quantity of good $i$ consumed per unit of labor. For this reason, if workers spend all of their income, the following equation is satisfied:

$$
\omega_{1}{ }^{*} C^{\mathrm{T}} p^{+}\left(1+r_{1}\right)=\omega_{1} C^{\mathrm{T}} p^{+}\left(1+r_{1}\right) .
$$

Replacing $C$ by ${ }^{*} C$ in $Æ$ does not alter prices or the profit rate in system (27) neither the growth rate in system (28). Indeed, on the one hand, it follows from Equation (38) that $p^{+}$and $r_{1}$ satisfy the last equation of system (27) and, by hypothesis, they also meet the other equations. In addition, $Æ$ is still indecomposable, implying that the system formed by Equations (20), (24), (26) and (27) have a single solution, as well as the system formed by Equations (28) and (29). On the other hand, since the replacement does not alter prices or the profit rate, it follows from Equation (26) that the value of $\lambda_{E}$ has not changed, and therefore, according to Equation (33), the growth rate is still equal to $g_{1}$, although the vector $q$ normally would have changed, as can be inferred from system (34). For this reason, the roles played by the bundle of goods consumed by workers in systems (27) and (28) are not symmetric regarding vectors $p^{+}$and $q$.

\section{The Balanced-Growth Path}

Given a level of $r \in[0, R[$, let $q$ be the vector determined by Equations (28) and (29). Multiplying, for each $j \leq n$, equation $j$ in (19) by the coordinate $q_{j}$ and also multiplying Equation (25) by $q_{n+1}$, we obtain the following system:

$$
\begin{gathered}
\sum_{i} a_{i j} q_{j} p_{i}(1+r)+a_{n+1, j} q_{j} p_{n+1}(1+r)=q_{j} p_{j} \quad j=1,2, \cdots, n \\
\sum_{i} \omega a_{i, n+1} q_{n+1} p_{i}(1+r)=q_{n+1} p_{n+1} .
\end{gathered}
$$

According to Equations (34), (35) and (36) this is an homothetic system in which the ratio between the quantity produced of each good and the amount of the same good consumed is equal to $1+r$. In this regard, for each $k=1,2, \cdots, n+1$, the surplus of good $k$, represented with $s_{k}$, is the quantity produced of $k$ net of the amount consumed of $k$ in the industrial system, vector $s=\left(s_{1}, s_{2}, \cdots, s_{n+1}\right)$ represents the economic surplus. The following proposition relates, on the one hand, investment and profit in each industry and, on the other hand, consumption and surplus in the whole industry.

Proposition 7. In the balanced-growth path, for each good, the amount of investment and of profit in the industry producing the good are equal to the value, respectively, of the quantity of that good consumed and the surplus of that good produced in the whole industry.

Proof. For each $i$, multiply by $p_{i} /(1+g)$ both sides of equation $i$ in system (34) and also multiply both sides of Equation (35) by $p_{n+1} /(1+g)$. The results are:

$$
\begin{gathered}
\sum_{j} a_{i j} q_{j} p_{i}+\omega a_{i, n+1} q_{n+1} p_{i}=q_{i} p_{i} /(1+g) \quad i=1,2, \cdots, n \\
\sum_{j} a_{n+1, j} q_{j} p_{n+1}=q_{n+1} p_{n+1} /(1+g) .
\end{gathered}
$$

The left-hand side of each one of these equations is the value of the total consumption of the corresponding good in the system. Now, dividing by $(1+r)$ both sides of each one of the equations of the system formed by Equations (39) and (40), we obtain:

$$
\begin{gathered}
\sum_{i} a_{i j} q_{j} p_{i}+a_{n+1, j} q_{j} p_{n+1}=q_{j} p_{j} /(1+r) \quad j=1,2, \cdots, n \\
\sum_{i} \omega a_{i, n+1} q_{n+1} p_{i}=q_{n+1} p_{n+1} /(1+r) .
\end{gathered}
$$

The left-hand side of each one of these equations is the investment made in the corresponding industry which, in the case of industry $n+1$, consists in the households' income (see Equation (32)). It follows from Equation (36) that, for each $k$, the left-hand side of the equation corresponding to $k$ in the system formed by Equations (41) 
and (42) is equal to the left-hand side of the equation corresponding to $k$ in the system formed by Equations (43) and (44). Therefore, we can establish the following equation system:

$$
\begin{gathered}
\sum_{j} a_{k j} q_{j} p_{k}+\omega a_{k, n+1} q_{n+1} p_{k}=\sum_{i} a_{i k} q_{k} p_{i}+a_{n+1, k} q_{k} p_{n+1} \quad k=1,2, \cdots, n \\
\sum_{j} a_{n+1, j} q_{j} p_{n+1}=\sum_{i} \omega a_{i, n+1} q_{n+1} p_{i} .
\end{gathered}
$$

This proves the first part of the proposition. To prove the second part, it suffices to multiply the left-hand side of each one of these equations by $g$ and its right-hand side by $r$.

According to this proposition, in the case of the set of households, the rate of profit measures the growth of the quantity of labor employed in the industrial system. The corresponding profit consists in the increase in the households' income due to this growth.

\section{Sraffa's Standard System}

For comparative purposes, in this Section, the quantity produced of each good in Equation (3) is used as the unit of measure for the quantities of that good. In this manner, $x_{j}=1 \forall j$ (see Benítez Sánchez [15]) and the net product of systems (3) and (4) are equal. I also assume that the quantities of labor are measured with the sum of labor employed in system (4) so that:

$$
\sum_{j} l_{j}=1
$$

Let $w$ be the fraction of the value of the net product corresponding to the wages paid at the end of production. Then,

$$
w=\mathrm{w}(1+r) \text {. }
$$

Equations (9) and (47) imply that $a_{i, n+1}=c_{i}$ for each $i$. Thus, it follows from Equations (21) and (23) that $\mathrm{w}=p_{n+1}$. This result together with Equation (48) implies that $w=p_{n+1}(1+r)$. Substituting in system (19) $p_{n+1}(1+r)$ by $w$ and also substituting $a_{n+1, j}$ by the right-hand side of Equation (8), yields:

$$
\sum_{j} a_{i j} p_{j}(1+r)+l_{i} w=p_{i} \quad i=1,2, \cdots, n
$$

This is the model of surplus economy studied by Sraffa [5], which enable us to calculate the prices and the distribution of income between wages and profits for each level of the profit rate and, alternatively, the prices and the rate of profit for each level of $w$ (e.g., Krause [16]; Nikaido and Kobayashi [17]; Samuelson [18]; Schefold [19]; White [20]). Systems composed of, on the one hand, Equations (20), (24), (26) and (27) and, on the other hand, Equations (20) and (49) determine the same prices for each level of $r \in[0, R[$. Therefore, the properties of prices are the same in the two systems.

However, it should be noted that unlike Sraffa's model, in which the number of homothetic merchandises is finite (see Benítez Sánchez [21]), the closed Leontief's model allows us to build a particular homothetic merchandise for each level of $r \in[0, R[$. Moreover, each one of these merchandises contains every good and not only basic goods, that is, those goods producing every good in system (49). Indeed, the system formed by Equations (39) and (40) is a standard system that determines the same relative prices as system (49) for the given value of $r$. For other values of $r \in[0, R[$, that system determines the same prices as system (49) provided that $\omega$ is modified according to Equation (24), which normally causes the system to stop being homothetic. Therefore, the procedure followed here allows the building of a standard system for each $r \in[0, R[$ which determines the same prices as system (49) for that particular level of $r$, but not necessarily for the other levels of this variable. As shown by Benitez [21], the existence of several standard systems build upon the data corresponding to a single production program permits to prove that the standard commodity, contrarily to Sraffa's thesis, is not an invariable measure of value.

It is worth adding that, for Sraffa ([5], pp. 6-11), the economic surplus is equal to the net product. The definition of economic surplus adopted here is closer to the use of this term by Marx ([22], pp. 329-332). However, unlike Marx's definition, in this paper, the economic surplus includes the increase of the labor force. Furthermore, a technical advantage of the model introduced here is to represent the economy by means of an indecomposable matrix even in the case that the coefficient matrix of the open economy is decomposable, which simplifies the analysis. 


\section{Conclusion}

This work shows an application of Leontief's closed model that, as far as I am aware, has not been explored previously. Such application is the study of income distribution between wages and profits when the rate of profit is the same in all industries. The results are consistent with those of Sraffa's model, except for the fact that in Leontief's model it is possible to build a standard system for each level of income distribution. This system, except for the scale of production and the units of measure employed, is equal to any whole-industry production process taking place within the balanced-growth path corresponding to Leontief's closed model for the given level of income distribution. Furthermore, in the balanced-growth path, for each good, the amounts of investment and profit in the industry producing the good are equal to the value, respectively, of the quantity of that good consumed and the surplus of that good produced in the whole industry. For this reason, for the set of households, included in the model as a particular industrial branch, the common profit rate measures the growth of the labor force. Unlike von Neumann's model, the balanced growth-path corresponding to Leontief's closed model shows explicitly the quantities of labor used in each industry, the quantities of goods consumed by workers and the growth of the labor force. Under a weak assumption, the growth rate is independent of worker's choice.

\section{Acknowledgements}

I am grateful to an anonymous referee for helpful comments and suggestions.

\section{References}

[1] Berman, A. and Plemmons, R.J. (1994) Nonnegative Matrices in the Mathematical Sciences. SCIAM, Philadelphia. http://dx.doi.org/10.1137/1.9781611971262

[2] Dorfman, R., Samuelson, P. and Solow, R. (1986) Linear Programming and Economic Analysis. Dover Publications Inc., New York.

[3] Leontief, W. (1960) The Structure of the American Economy 1919-1939. 2nd Edition, Oxford University Press, New York.

[4] ten Raa, T. (2005) The Economics of Input-Output Analysis. Cambridge University Press, New York.

[5] Sraffa, P. (1960) Production of Commodities by Means of Commodities. Cambridge University Press, Cambridge, UK.

[6] von Neumann, J. (1945) A Model of General Economic Equilibrium. The Review of Economic Studies, 13, 1-9. http://dx.doi.org/10.2307/2296111

[7] Seneta, E. (1981) Non-Negative Matrices and Markov Chains. 2nd Edition, Springer Verlag, New York. http://dx.doi.org/10.1007/0-387-32792-4

[8] Takayama, A. (1985) Mathematical Economics. 2nd Edition, Cambridge University Press, New York.

[9] Serre, D. (2002) Matrices: Theory and Applications. Springer-Verlag, New York.

[10] Zhang, F.Z. (2011) Matrix Theory: Basic Results and Techniques. 2nd Edition, Springer-Verlag, New York. http://dx.doi.org/10.1007/978-1-4614-1099-7

[11] Abex, M. and Perobelli, F.S. (2010) Solow Meets Leontief: Economic Growth and Energy Consumption. Energy Economics, 32, 43-53. http://dx.doi.org/10.1016/j.eneco.2009.05.004

[12] Flissner, P. (1990) Dynamic Leontief Models in the Bed Test. Structural Change and Economic Dynamics, 1, $321-357$. http://dx.doi.org/10.1016/0954-349X(90)90008-V

[13] Kiedrowski, R. (2001) A Turnpike Theorem in the Closed Dynamic Leontief Model with a Singular Matrix of Capital Coefficients. Economic Systems Research, 13, 209-222. http://dx.doi.org/10.1080/09537320120064885

[14] Wurtele, Z.S. (1960) Equilibrium in a Uniformly Expanding Closed Leontief-Type Economy. The Review of Economic Studies, 28, 23-28. http://www.jstor.org/stable/2296245 http://dx.doi.org/10.2307/2296245

[15] Benítez Sánchez, A. (2015) An Extension of the Hawkins and Simon Condition Characterizing Viable Techniques. Economics Research International, 2015, Article ID: 181284. http://ssrn.com/abstract=2653932

[16] Krauze, U. (1981) Heterogeneous Labour and the Fundamental Marxian Theorem. Review of Economic Studies, 48, 173-178. http://dx.doi.org/10.2307/2297130

[17] Nikaido, H. and Kobayashi, S. (1978) Dynamics of Wage-Price Spirals and Stagflation in the Leontief-Sraffa System. International Economic Review, 19, 83-108. http://dx.doi.org/10.2307/2526395 
[18] Samuelson, P.A. (2001) A Ricardo-Sraffa Paradigm Comparing Gains from Trade in Inputs and Finished Goods. Journal of Economic Literature, 39, 1204-1214. http://dx.doi.org/10.1257/jel.39.4.1204

[19] Schefold, B. (1980) Von Neumann and Sraffa: Mathematical Equivalence and Conceptual Difference. The Economic Journal, 90, 140-156. http://dx.doi.org/10.2307/2231661

[20] White, G. (1996) Capacity Utilization, Investment and Normal Prices: Some Issues in the Sraffa-Keynes Synthesis. Metroeconomica, 47, 281-304. http://dx.doi.org/10.1111/j.1467-999X.1996.tb00393.x

[21] Benítez Sánchez, A. (1986) L’Étalon dans la Théorie de Piero Sraffa. Cahiers d’Économie Politique, No. 12, $136-146$. http://ssrn.com/abstract=2505245

[22] Marx, K. (1990) Capital, Volume I. Penguin Books, London. 


\section{Appendix: A Numerical Example}

In this Appendix, I consider a system that produces a unit of Good 1 consuming half a unit from the same good, and a unit of work. Then:

$$
Æ=\left[\begin{array}{cc}
1 / 2 & \omega / 2 \\
1 & 0
\end{array}\right] .
$$

I further assume that $\omega=1 / 2$.

\section{A.1. The Growth Rate}

Substituting $\omega$ by $1 / 2$ in $Æ$ yields:

$$
\nexists=\left[\begin{array}{cc}
1 / 2 & 1 / 4 \\
1 & 0
\end{array}\right] .
$$

Thus, the system formed by Equations (30) and (31) can be written in the following way:

$$
\begin{gathered}
0.5 q_{1}+0.25 q_{2}=\lambda_{\star} q_{1} \\
q_{1}=\lambda_{Æ} q_{2}
\end{gathered}
$$

Substituting into the first equation $q_{1}$ for $\lambda_{Æ} q_{2}$ results in:

$$
0.5 \lambda_{Æ} q_{2}+0.25 q_{2}=\lambda_{Æ}^{2} q_{2} \text {. }
$$

Dividing both sides of the equation by $q_{2}$ and regrouping, yields:

$$
\lambda_{Æ}^{2}-0.5 \lambda_{Æ}-0.25=0 .
$$

Therefore $\lambda_{Æ}=\left\{0.5 \pm[0.25+4(0.25)]^{1 / 2}\right\} / 2$. Taking 7 decimal digits, this results in $\lambda_{Æ}=0.8090169$. Thus, it follows from Equation (33) that:

$$
g=0.2360679
$$

Moreover, taking into account Equation (29), we obtain $q_{1}=1$ and $q_{2}=q_{1} / \lambda_{Æ}=1.2360679$

\section{A.2. Prices and Income Distribution}

System (27) can be written as follows:

$$
\begin{gathered}
\left(0.5 p_{1}+p_{2}\right)(1+r)=p_{1} \\
0.25 p_{1}(1+r)=p_{2}
\end{gathered}
$$

According to Equations (36) and (A.3), in this system $r=0.2360679$. Given that the net product is $0.5 p_{1}$ we have $p_{1}=2$. Substituting $p_{1}$ and $r$ for their values in the second equation yields the wage $p_{2}=0.5(1.2360679)=0.6180339$. The capital invested in the first enterprise is $0.5 p_{1}+p_{2}=1.618039$ and the corresponding profit results multiplying this capital by $r$ which yields $(1.618039)(0.2360679)=0.381967$. Adding the profits to the wage results the value of the net product.

\section{A.3. The Balanced-Growth Path}

To build a system of type (27) which is in the balanced-growth path for $r=0.2360679$, we multiplying each equation $i$ in system (A.4) for the corresponding coordinate $q_{i}$. The result is:

$$
\begin{gathered}
\left(0.5 p_{1}+p_{2}\right)(1+r)=p_{1} \\
0.3090269 p_{1}(1+r)=1.2360679 p_{2}
\end{gathered}
$$

This system is in a balanced-growth path with $g=0.2360679$ and $\mathrm{w}=0.3090269 p_{1}=0.618052$. The set of households obtains a profit that consists in the value of the increase of the labor force. 
Finally, Sraffa's system of type (49) that corresponds to this economy is:

$$
0.5 p_{1}(1+r)+w=p_{1} .
$$

According to Equation (48) when $r=0.2360679$ it results $w=(0.6180339)(1.2360679)=0.7639319$. If the wage is paid at the end of production the profit is $0.5 p_{1} r=(0.5)(2)(0.2360679)=0.2360679$, summing up wage and profit yields the net product. Since system (A.6) is homothetic, it is a standard system. Or, system (A.5) is also a standard system determining the same system of relative prices for $r=0.2360679$. 